\title{
MYOSITIS IN MIXED CONNECTIVE TISSUE DISEASE
}

\author{
A unique syndrome characterized by \\ immunohistopathologic elements of both \\ polymyositis and dermatomyositis
}

\author{
Maria Angela A.G. Vianna ${ }^{1}$, Claudia T.L. Borges ${ }^{1}$, Eduardo F. Borba ${ }^{1}$, \\ Maria Teresa C. Caleiro ${ }^{1}$, Eloisa Bonfá1, Suely K.N. Marie ${ }^{2}$
}

ABSTRACT - Objective: To characterize the inflammatory cells, the expression pattern of adhesion molecules (ICAM-1 and VCAM-1), membrane attack complex (C5b-9), and major histocompatibility complex (MHC) antigens in muscle biopsy of mixed connective tissue disease (MCTD). Method: We studied 14 patients with MCTD, and compared to 8 polimyositis (PM) patients, 5 dermatomyositis (DM) and 4 dystrophies. Inflammatory cells were examined for $\mathrm{CD}^{+}, \mathrm{CD} 8^{+}$, memory and naïve $\mathrm{T}$ cells, natural killer cells, and macrophages. Expression of MHC-I and -II, ICAM-1, VCAM-1 and C5b -9 were characterized on muscle fibers and vessels. Results: Morphological analysis displayed a pattern of PM. Immunohistochemical study revealed a decreased number of capillaries, predominance of $\mathrm{CD} 4^{+}$and $\mathrm{B}$ cells in perivascular regions and predominance of $\mathrm{CD}^{+}$and $\mathrm{CD} 45 \mathrm{RO}^{+}$in endomysial regions. The expression of $\mathrm{MHC}-\mathrm{I}$ on vessels and on degenerated muscle fibers, MHC-II expression on vessels and perifascicular muscle fibers, and the expression of ICAM-1 / VCAM-1 on endothelial cells indicated both vascular and cellular-immune mediated processes causing the muscular lesion. Condusion: Our findings revealed a mixed mechanism in MCTD, both vascular involvement as DM, and cell-mediated like PM.

KEY WORDS: mixed connective tissue disease, myositis, major histocompatibility complex, adhesion molecules, membrane attack complex, lymphocyte phenotyping.

\begin{abstract}
Miosite na doença mista do tecido conectivo: achados imunopatológicos de polimiosite e dermatomiosite

RESUMO - Objetivo: Caracterizar as células do infiltrado inflamatório, o padrão de expressão das moléculas de adesão (ICAM-1 e VCAM-1), complexo de ataque à membrana (C5b-9) e antígenos de histocompatibilidade maior (M HC) em biópsias musculares de patientescom doença mista do tecido conectivo (DMTC). Método: Foram estudados14 pacientes com DMTC e comparadas com 8 pacientes com polimiosite (PM), 5 com dermatomiosite (DM) e 4 com distrofias. As células inflamatóriasforam caracterizadas como CD4+, CD8 ${ }^{+}$, células T de memória (CD45RO+) e virgens, células "natural killer" e macrófagos. As expressões de MHC-I e -II, ICAM-1, VCAM-1 e C5b-9 foram caracterizadas em fibras musculares e vasos. Resultados: A análise morfológica demonstrou um padrão tipo PM. O estudo imuno-histoquímico revelou diminuição do número de capilares, predomínio de células $\mathrm{CD}^{+}{ }^{+}$e $\mathrm{B}$ nas regiões perivasculares e predomínio de $\mathrm{CD} 8^{+}$e $\mathrm{CD} 45 \mathrm{RO}^{+}$ nas regiões endomisiais. A expressão de MHC-I nosvasose nasfibras degeneradas, MHC-II nos vasose fibras perifascicularese expressão de ICAM-1 / VCAM-1 no endotélio indicaram uma associação de processos vascular e imune-celular mediando a lesão muscular. Conclusão: Os achados revelaram duplo mecanismo na DMTC, imune-celular como na PM e vascular como na DM.

PALAVRAS-CHAVE: doença mista do tecido conectivo, miosite, complexo de histocompatibilidade maior, moléculas de adesão, complexo de ataque à membrana, fenotipagem linfocitária.
\end{abstract}

The rather heterogeneous group of inflammatory myopathies comprises three major and distinct subsets: polymyositis (PM), dermatomyositis (DM), and inclusion body myositis (IBM). Each group has itscharacteristic clinical, immunopathological, and morphological featureseven when associated with

${ }^{1} \mathrm{MD}, \mathrm{PhD}$, Division of Rheumatology, Faculdade de Medicina da Universidade de São Paulo, São Paulo, SP, Brazil (FMUSP); ${ }^{2 M D}$, PhD, Department of Neurology FMUSP. Study supported by FAPESP, \#98/16291-2.

Received 30 March 2004, received in final form 1 July 2004. Accepted 10 August 2004.

Dra. Suely Kazue Nagahashi Marie - Avenida Dr. Arnaldo 453, 4 andar / sala 4110 - Faculdade de Medicina USP LIM 15 - $01246-903$ - São Paulo SP Brasil. FAX: (55 11) 3062-0620 
other systemic diseases ${ }^{1}$. Mixed connective tissue disease (MCTD) described by Sharp et al. ${ }^{2}$ in 1972 is an inflammatory disease which is clinically characterized by features of systemic lupus erythematosus, systemic sclerosis and polymyositis, associated with high titers of circulating antinuclear antibody with specificity for nudear ribonucleoprotein (RNP).

During the course of this disease, the majority of patientscomplains of myalgia, muscle tenderness or fatigue ${ }^{2}$. Clinical evidence of myositis defined as symmetrical proximal weakness, electromyographic abnormalities, or altered muscle enzymes were reported in almost three-fourths of 25 MCTD patients in the original series of Sharp et al. ${ }^{2}$ and in nine of 20 patients described by Bennett and O'Connell ${ }^{3}$. Despite these reports, the pattern of myopathy detected in MCTD ispoorly characterized in the literature. In contrast, there isa growing body of evidence that HLA class I-restricted cytotoxic T cells-mediated response against surface antigens expressed by muscle fibersisthe primary pathogenic mechanism in PM and IBM ${ }^{4}$, whereasDM involvespredominantly an antibody or immune-complex-mediated response against a vascular-endothelial component ${ }^{5,6}$. Moreover, the studies that have characterized the muscle involvement in MCTD ${ }^{2,3,7}$ antedated the Kasukawa classification criteria ${ }^{8}$ actually applied for this disease. According to some authors ${ }^{2,3,7-9}$, the musde involvement is a dassic inflammatory myositissimilar to that detected in PM when analyzed by histology and histochemistry. Nonetheless, conventional light microscopy and staining techniques used in these studies could not distinguish the real significance of cellular infiltrates.

We therefore have designed the present study to characterize the infiltrating mononuclear cells, the expression of major histocompatibility complex (MHC) proteins, aswell asthe adhesion moleculesand complement activation, in order to better understand the mechanism of muscle cell injury in MCTD.

\section{METHOD}

Patients- Fourteen patients with MCTD [12 females (F), 2 males (M), age 24-54 years] prospectively followed in our outpatient Rheumatology Clinic at the University of São Paulo were selected for this study (Table 1). All MCTD patientsmet the classification criteria of Kasukawa ${ }^{8}$ and had clinical signs of myopathy (weaknessor elevated enzyme levels) at the time of evaluation. Muscle biopsy specimenswere obtained from clinically weak brachial biceps muscle after written informed consent. Four MCTD patients with muscular symptoms had biopsiestaken before treatment in a recent diagnosis of MCTD.
The other ten MCTD patients were biopsied in order to elucidate the muscular symptoms despite treatment of MCTD systemic activity. Five of these 10 MCTD patients were taking prednisone for less than 6 months and the other five for 6 months or longer.

Eight PM patients (6F, 2M, age 27-57 years) and 5DM (3F, 2M , age 22-58 years) according to Bohan and Peter ${ }^{10,11}$ criteria were selected for control. Additionally, 4 patients (3M , 1F, age 20-50 years) with non-inflammatory neuromuscular diseases (NINMD) included X-linked, limb-girdle and facioscapulohumeral dystrophies were also included as controls (Table 1). All muscle biopsy of control patients were performed during active disease and before treatment, and also after written informed consent. No patients or controls had evidence of an associated malignancy.

This study was approved by local ethics committee.

Laboratorial data - Blood samples of MCTD patients and controls were collected within two weeks prior to biopsy. Muscle enzymes such as creatine kinase (CK), lactate dehydrogenase (LDH), aspartate (ASP) and alanine (ALT) amino transaminases were analyzed by standard techniques.

Autoantibody assay - Serum samples were also tested for the presence of anti-nuclear and cytoplasmic antibodies by indirect immunofluorescence using Hep-2 as substrate. Antibodies to RNP and Sm were detected by counterimmunoelectrophoresis ${ }^{12}$, and antibodies to extractable nuclear antigens (ENA) were tittered by passive hemaglutination assay ${ }^{13}$. Crithidia luciliae was used to detect reactivity to double-stranded DNA (dsDNA) ${ }^{14}$. Antibodies to Jo-1 were determined by SDS-PAGE and immunoblotting, as previously described ${ }^{15}$.

Histopathological analysis- Routine standard histological and histochemical techniques were performed on muscle biopsies. Sequential frozen sectionswere stained with hematoxilin-eosin (H\&E), modified Gomori trichrome, periodic acid Schiff, cytochrome C oxydase (COX), NADH-tetrazolium-reductase, succinate dehydrogenase (SDH), adenosine triphosphatase ( $\mathrm{pH} 4.3$ and 9.4), alkaline and acid phosphatases ${ }^{16}$. Each biopsy specimen was coded and independently analyzed for inflammatory infiltrate (in endomysial, perimysial and perivascular sites), necrosis and fibrosis.

Immunohistochemical analysis - Immunoreagents used for characterization of inflammatory infiltrate and surface molecules expressed on muscle fiber were: memory T cells (CD45RO), clone UCHL1, DAKO/M0742, dilution 1:200; naïve T cells (CD45RA), 4KB5, DAKO/M 0754, 1:200; CD4+T cells, OPD4, DAKO/M 834, 1:150; CD8+T cells, C8/144B, DAKO/M 7103, 1:200; macrophages (CD68) EBM 11, DAKO/M0718, 1:1600; natural killer (NK), NK1, 
Table 1. Data of cases included in the study concerning age, gender, vascular density, expression of MHC-I, MHC-II, ICAM-1, VCAM-1 and C5b-9 at immunohistochemical preparations of frozen muscle biopsies.

\begin{tabular}{|c|c|c|c|c|c|c|c|c|c|c|c|c|c|}
\hline \multirow[t]{2}{*}{ Case } & \multirow[t]{2}{*}{ Gender } & \multirow{2}{*}{$\begin{array}{c}\text { Age } \\
\text { (years) }\end{array}$} & \multirow{2}{*}{$\begin{array}{l}\text { Vascular } \\
\text { density }\end{array}$} & \multicolumn{2}{|c|}{ MHC-I } & \multicolumn{2}{|c|}{ MHC-II } & \multicolumn{2}{|c|}{ ICAM-1 } & \multicolumn{2}{|c|}{ VCAM-1 } & \multicolumn{2}{|c|}{ C5b-9 } \\
\hline & & & & if & $\mathrm{s}$ & if & $\mathrm{s}$ & $v$ & if & $v$ & if & $v$ & if \\
\hline \multicolumn{14}{|c|}{ MCTD } \\
\hline 1 & $\mathrm{~F}$ & 42 & 0.23 & + & - & + & + & + & + & + & - & + & - \\
\hline 2 & $\mathrm{~F}$ & 32 & 0.30 & - & - & + & + & + & - & + & - & + & - \\
\hline 3 & $M$ & 25 & 0.83 & - & - & + & + & + & + & + & - & + & - \\
\hline 4 & $\mathrm{~F}$ & 54 & 0.21 & - & - & + & + & + & + & + & - & + & - \\
\hline 5 & $\mathrm{~F}$ & 24 & 0.34 & + & $H+$ & - & - & + & - & + & - & + & - \\
\hline 6 & $\mathrm{~F}$ & 27 & 0.27 & - & - & - & - & + & - & + & + & + & - \\
\hline 7 & $\mathrm{~F}$ & 31 & 0.38 & - & - & - & - & + & + & + & - & + & + \\
\hline 8 & $\mathrm{~F}$ & 49 & 0.33 & - & - & - & - & + & - & + & - & + & + \\
\hline 9 & $\mathrm{~F}$ & 39 & 0.45 & + & + & + & + & + & + & + & - & + & + \\
\hline 10 & $\mathrm{~F}$ & 48 & 0.17 & + & - & - & - & + & - & + & - & + & - \\
\hline 11 & $\mathrm{~F}$ & 29 & 0.41 & - & - & - & - & + & - & + & - & + & - \\
\hline 12 & $F$ & 38 & 0.22 & - & - & - & - & + & - & + & - & + & + \\
\hline 13 & $F$ & 26 & 0.53 & - & - & - & - & + & - & + & - & + & - \\
\hline 14 & $M$ & 34 & 0.40 & - & - & - & - & + & - & + & - & + & - \\
\hline \multicolumn{14}{|l|}{ PM } \\
\hline 15 & $F$ & 47 & 0.82 & $\mathrm{H}+$ & $+1+$ & - & - & + & - & + & - & $+1+$ & $+1+$ \\
\hline 16 & $F$ & 35 & 0.64 & + & + & + & - & + & - & - & - & + & - \\
\hline 17 & $M$ & 27 & 0.61 & $H+$ & $H+$ & + & - & + & + & + & + & + & + \\
\hline 18 & $\mathrm{~F}$ & 57 & 0.46 & $H+$ & $+1+$ & $H+$ & - & + & - & + & - & + & - \\
\hline 19 & $\mathrm{~F}$ & 32 & 0.43 & - & - & + & - & + & - & + & - & + & + \\
\hline 20 & $\mathrm{~F}$ & 40 & 0.54 & + & + & - & - & - & - & - & - & + & - \\
\hline 21 & $M$ & 50 & 1.08 & $\mathrm{HH}$ & $+1+$ & + & + & + & - & + & - & + & - \\
\hline 22 & $\mathrm{~F}$ & 50 & 0.29 & - & - & + & - & + & - & + & - & + & + \\
\hline \multicolumn{14}{|l|}{ DM } \\
\hline 23 & $F$ & 22 & 0.26 & $H+$ & $+1+$ & - & - & $H+$ & - & + & + & + & + \\
\hline 24 & $\mathrm{~F}$ & 44 & 0.18 & + & $H+$ & + & - & + & + & + & + & + & + \\
\hline 25 & $\mathrm{~F}$ & 24 & 0.19 & + & + & + & + & $\mathrm{H}$ & $+1+$ & + & + & + & $+1+$ \\
\hline 26 & $M$ & 58 & 0.33 & + & $+1+$ & + & + & + & + & + & - & + & + \\
\hline 27 & $M$ & 35 & 0.24 & + & + & + & + & $H$ & + & + & - & + & + \\
\hline
\end{tabular}

NINMD

\begin{tabular}{|c|c|c|c|c|c|c|c|c|c|c|c|c|c|}
\hline 28 & $M$ & 50 & 0.38 & - & - & - & - & + & - & - & - & + & - \\
\hline 29 & $M$ & 27 & 0.16 & - & - & - & - & + & - & - & - & - & - \\
\hline 30 & $M$ & 40 & 0.87 & - & + & - & - & + & - & + & - & + & - \\
\hline 31 & $\mathrm{~F}$ & 20 & 0.38 & - & - & - & - & + & - & - & - & - & - \\
\hline
\end{tabular}

MCTD, Mixed connective tissue disease; PM, polimyositis; DM, dermatomyositis; NINMD, non-inflammatory muscle disease; vascular density calculated as number of vessels/number of fibers; $\mathrm{v}$, vessels; if, invaded fiber; $\mathrm{S}$, sarcolemmal membrane; - no expression in structures analyzed: + expression observed in $<25 \%,++<50 \%,++<75 \%$ of structures analyzed.

DAKO/M 1014, 1:100; B cells (CD20), L26, DAKO/M 755, 1:200; MHC dassI, W6/32, DAKO/M 0736, 1:100; MHC dass II, CD3/43, DAKO/M0775, 1:100; ICAM-1 (CD54), 6.5B5, DAKO/M 7063, 1:200; VCAM-1 (CD106), 1.4C3, DAKO/M 7106, 1:100; C5b-9, aE11, DAKO/M 0777, 1:200.

Immunohistochemical procedure consisted by serial $4 \mu$ frozen sections which were fixed for 10 minutes in acetone at 4 ㅇ $C$ and then washed in distilled water followed by phosphate-buffered-saline (PBS 0.01M, pH 7.4) for 5 minutes. Endogenousperoxidase wasblocked with $\mathrm{H}_{2} \mathrm{O}_{2} 3 \%$ in absolute methanol four times, 5 minuteseach.
After a rinse in distilled water followed by PBSfor 5 minutes, the primary antibody was added diluted in bovine serum albumine (BSA) $1 \%$, sodium azide $0.1 \%$ and PBS. Sequential incubation in a wet chamber at $370 \mathrm{C}$ for 30 minutes was followed by an overnight incubation at 4 C. The secondary antibodies were applied after three timeswashed by 5 minutes in PBS by 3 different techniques:

$\mathrm{LSAB}^{+}$procedure (for CD45RO, CD45RA, NK, CD20, CD68) - A biotinylated anti-mouse, anti-rabbit and antigoat immunoglobulins (DAKO, A/S Denmark; code 
K0690) wasapplied for 30 minutes at 370 C. Subsequently, it was incubated with a chromogenic substrate solution for peroxidase 3,3'-diaminobenzidine tetrahydrochloride (DAB). After a final rinse, haematoxylin counterstaining was performed. The slides were mounted and coverslipped with a permanent medium (Enterllan).

StreptABComplex/HRP procedure (for MHC-I, -II, ICAM-1, VCAM-1, C5b-9)) - The prepared secondary biotinylated goat and rabbit immunoglobulin (StreptABComplex/HRP-Duet, mouse/rabbit, DAKO, S/A Denmark; code K0492) was applied for 30 minutes at 370 C and rinsed in PBS. Subsequently, it was incubated with a chromogenic substrate solution for peroxidase 3,3'-diaminobenzidine tetrahydrochloride (DAB). After a final rinse, haematoxylin counterstaining was performed. The slideswere mounted and coverslipped with Enterllan.

EnVision-AP procedure (for $\mathrm{CD}_{4}^{+}, \mathrm{CD}^{+}$) - A conjugated polymer with alkaline phosphatase was applied for 30 minutes (DAKO, A/S Denmark; code K4016). After a further rinse with PBS, fast-red substrate-chromogen wasapplied for $10 \mathrm{~min}$, followed by haematoxylin counterstaining. The slides were mounted and coverslipped with a permanent medium.

For control purposesadditional sections were not incubated with primary antibody and lymphoid tissue was used as positive control for lymphocyte subtype antibody reactions.

Quantitative analysis- Each biopsy specimen wascoded and analyzed "blind" by the two investigators (MAAGV and SKNM). Ten random analyzed fields of $400 x$ represented the entire area of the specimen.

Analysis of inflammatory cells- $\mathrm{CD}^{+}, \mathrm{CD} 8^{+}, \mathrm{CD} 45 \mathrm{RO}$, CD45RA, NK, CD20, and CD68 were counted on the pe- rivascular and endomysial regions separately. The cells were counted using the program "CELL" which wasdeveloped in order to process images obtained by a digital camera attached to a microscope ("CELL", MEVIS- Medical Informatic Consulting, São Paulo, Brazil) and accepts images in TIF or JPEG format. This program allowsorganizing, rendering and calibrating a set of images, and is also able to identify and count up three different types of cells, in an automatic or semi-automatic way. All images are translated into RGB with 8 bits per channel ( 24 bits per pixel). The segmentation process is based in color masks, with adjustable range for each primary color. Rejection algorithmswere introduced based in cell area and form factor criteria. Cell borders could be drawn by the user, if necessary. The results presentation could be in the form of histograms and tables, including diameter, area, form factor and number of each type of cells.

Analysis of MHC-I, MHC-II, ICAM-1, Vcam-1 and C5b9 - Expression of those antigens were assessed by a semiquantitative method where: $(-)=$ no expression in structuresanalyzed; $(+)=$ expression observed in lessthan $25 \%$ of structures; $(++)=$ in lessthan $50 \% ;(+H)=$ in less than $75 \% ;(+1+1)=$ in 76 to $100 \%$ of structuresanalyzed.

Statistical analysis- Continuous data were expressed as mean and standard deviation or in median with minimum and maximum values. Comparison among groups and MCTD regarding continuous variables were performed using Kruskal-Wallistest. In case of statistical significance, multiple comparisons between groups were done using Wilcoxon rank sum test. Pearson'sChi-square test was used to compare groups regarding the proportion of patientswith $0 /+$ and $+\mathrm{H}+\mathrm{H}+$ to immunohistochemical parameters. Level of significance was set at $p \varangle 0.05$, and the SPSS ${ }^{\circledR}$ statistical system was used for all statistical calculations.

Table 2. Mean values of the myositis-associated enzymesin MCTD, PM, DM, and NINMD groups.

\begin{tabular}{lccccc}
\hline Parameter & $\begin{array}{c}\text { MCTD } \\
(\mathrm{n}=14)\end{array}$ & $\begin{array}{c}\text { PM } \\
(\mathrm{n}=8)\end{array}$ & $\begin{array}{c}\text { DM } \\
(\mathrm{n}=5)\end{array}$ & $\begin{array}{c}\text { NINMD } \\
(\mathrm{n}=4)\end{array}$ & $\mathrm{p}$ \\
\hline CK* & 523 & 1654 & 2781 & 1556 & 0.075 \\
& $(33-5030)$ & $(68-6219)$ & $(971-15000)$ & $(1184-1929)$ & \\
LDH & 746 & 492 & 1173 & 395 & 0.31 \\
& $(275-2052)$ & $(239-1311)$ & $(324-2355)$ & $(271-521)$ & \\
AST & 39 & 102 & 101 & 49 & 0.55 \\
& $(11-291)$ & $(31-482)$ & $(25-495)$ & $(44-98)$ & \\
ALT & 31 & 78 & 82 & 69 & 0.26 \\
& $(9-147)$ & $(37-263)$ & $(2-283)$ & $(44-94)$ & \\
\hline
\end{tabular}

MCTD, Mixed connective tissue disease; PM, polimyositis; DM, dermatomyositis; NINMD, non-inflammatory muscle disease; CK, creatine kinase; LDH, lactate dehydrogenase; AST, aspartate amino transaminase; ALT, alanine amino transaminase. 


\section{RESULTS}

Laboratorial data

MCTD patients had a significantly lower median CK level compared to DM ( $p=0.0142)$, but not significantly different from PM $(p=0.34)$ nor NINMM $(p=0.17)$. Similarly, no difference was detected for LDH, AST and ALT levels among groups (Table 2).

\section{Autoantibody assay}

All MCTD sera presented an uniformly positive speckled ANA with high titer anti-RNP and negative anti-Sm, anti-dsDNA and anti-Jol antibodies. All except one of DM patients presented a positive speckled ANA. On the other hand, 4 of 8 PM patients presented a positive speckled ANA and 2 of them also presented anti-Jol antibodies. In contrast, the NINMD group was invariably negative for the presence of all autoantibodies tested.

\section{Histological and histochemical findings}

All MCTD musde biopsies revealed an inflammatory cell infiltrate displaying a heterogeneous distribution, predominating in the perivascular, and endomysial regions (Fig 1A). Moreover, some perimysial vessels presented slight wall thickness increase (Figs 1B, 1C). Some necrotic and non-necrotic muscle fibers were surrounded by inflammatory cells, which were sparsely distributed among the fascicles (Fig 1A), and showed positivity on acid phosphatase reaction. In addition, the affected mus-

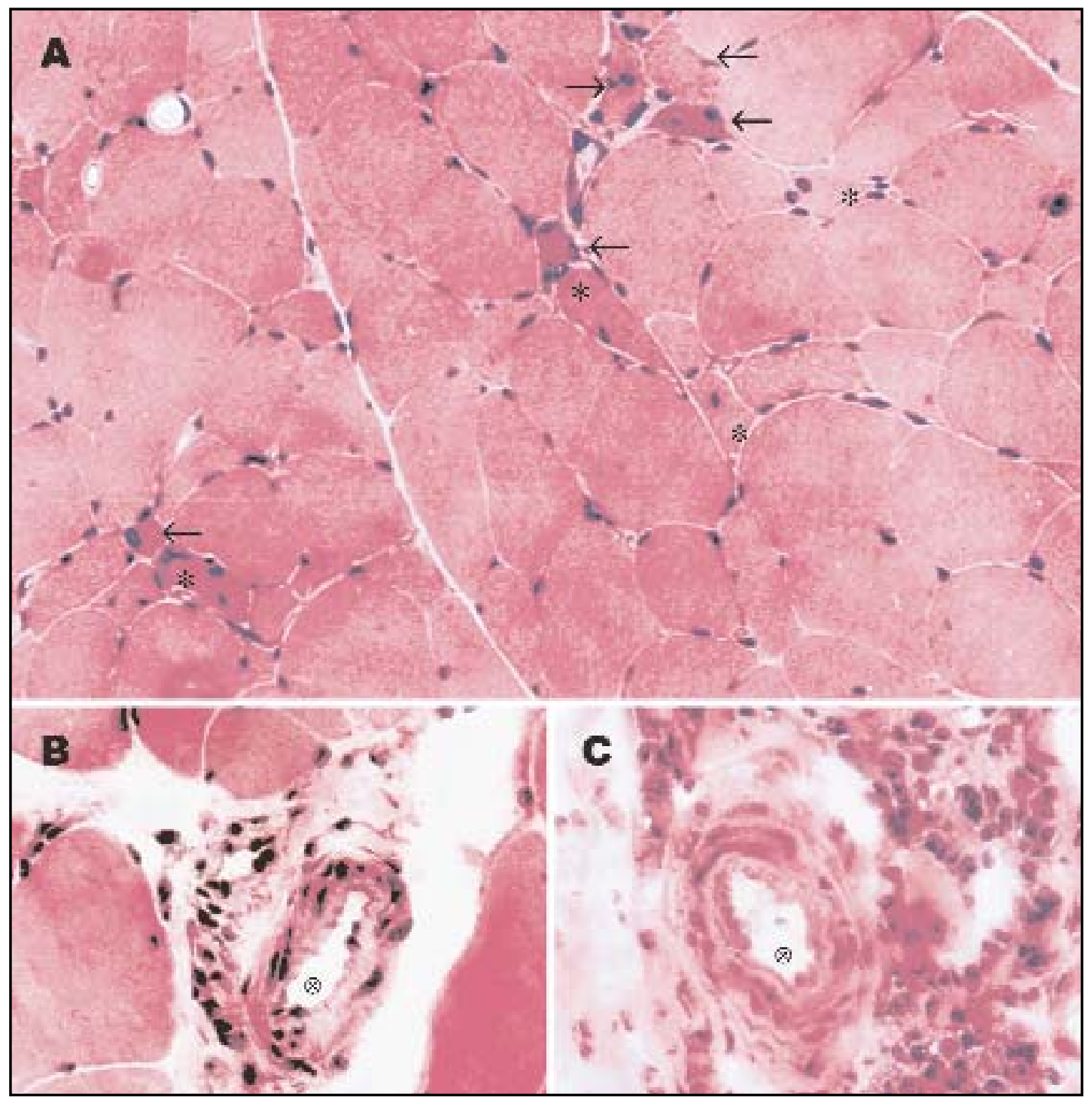

Fig 1. Histological transverse $4 \mu$ frozen sections of bíceps brachii from MCTD patients stained by bematoxilineosin (300X). A: shows a moderate variation on fiber size, degenerated fibers $(\rightarrow)$, and non-necrotic fibers invaded by inflammatory mononuclear cells (*) (Case 4). B and C: show perivascular inflammatory infiltration and increased thickness of the vessels walls $(\otimes)$ (Cases12 and 8, respectively). 


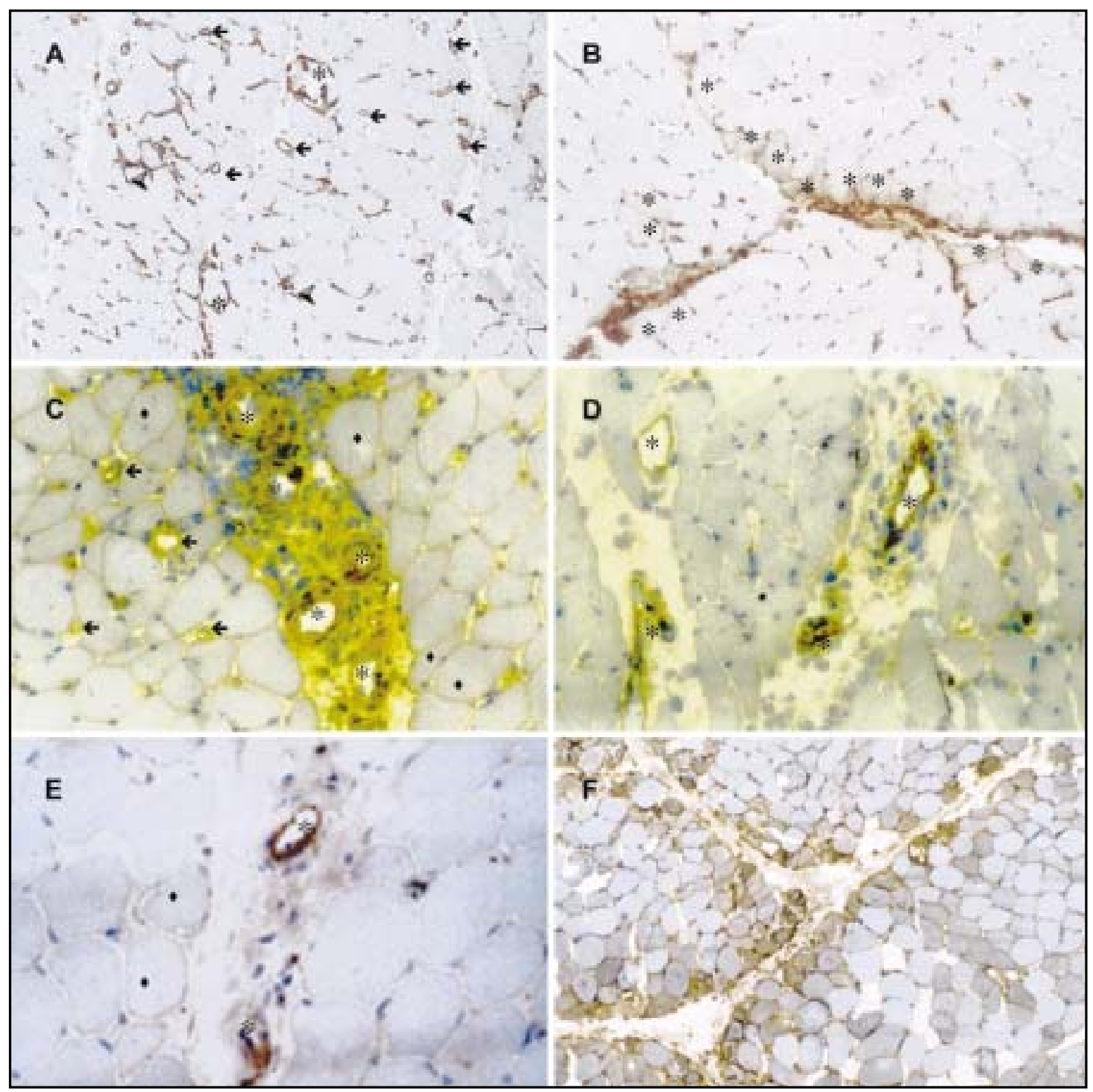

Fig 2. Immunohistochemical transverse $4 \mu$ frozen sections from MCTD patients prepared by StreptABCComplex technique (in brown) for MCH-I (A), MHC-II (B), ICAM-1 (C), VCAM-1 (D), C5b-9 (E), and in a DM case for MHC-II (F) (300x). A: Note the positive MHC-I expression on degenerated muscle fibers (*), capillaries ( ) and inflammatory cells ( ). B: Observe de positive MHC-II reaction on muscle fibers distributed at the perifascicular site. The positivity is seen in a reticular citoplasmic pattern and at the sarcolemmal membrane of those fibers (*). C: Positive reaction for ICAM-1 is observed on vessels (*) surrounded by inflammatory cells, on capillaries ( ), and at the sarcolemmal of nearby muscle fibers ( $t$ ). D: Similarly, the vessels (*) surrounded by inflammatory infiltrate show VCAM-1 expression. E: Positive reaction for C5b-9 is observed on vessels of the perimysial region (*). F: DM case prepared for MHC-II. Note the perifascicular atrophy, and the positivity of fibers at the perifascicular region, similar to the result observed on MCTD.

cle fibers demonstrated intermiofibrilar disorganization on oxidative reactions (NADH, SDH, and COX). Slight endomysial and perimysial connective tissue proliferation was observed in few (3/14) MCTD muscle biopsies.

In contrast, PM muscle specimens displayed an endomysium and perivascular inflammatory infiltra- te in a moderate intensity, with some of those cells surrounding and invading single non-necrotic muscle fibers. The necrotic and ghost fibers were also present.

On the other hand, DM biopsies exhibited the typical distribution of inflammatory cellson perivascular region, with a marked perifascicular atrophy. 


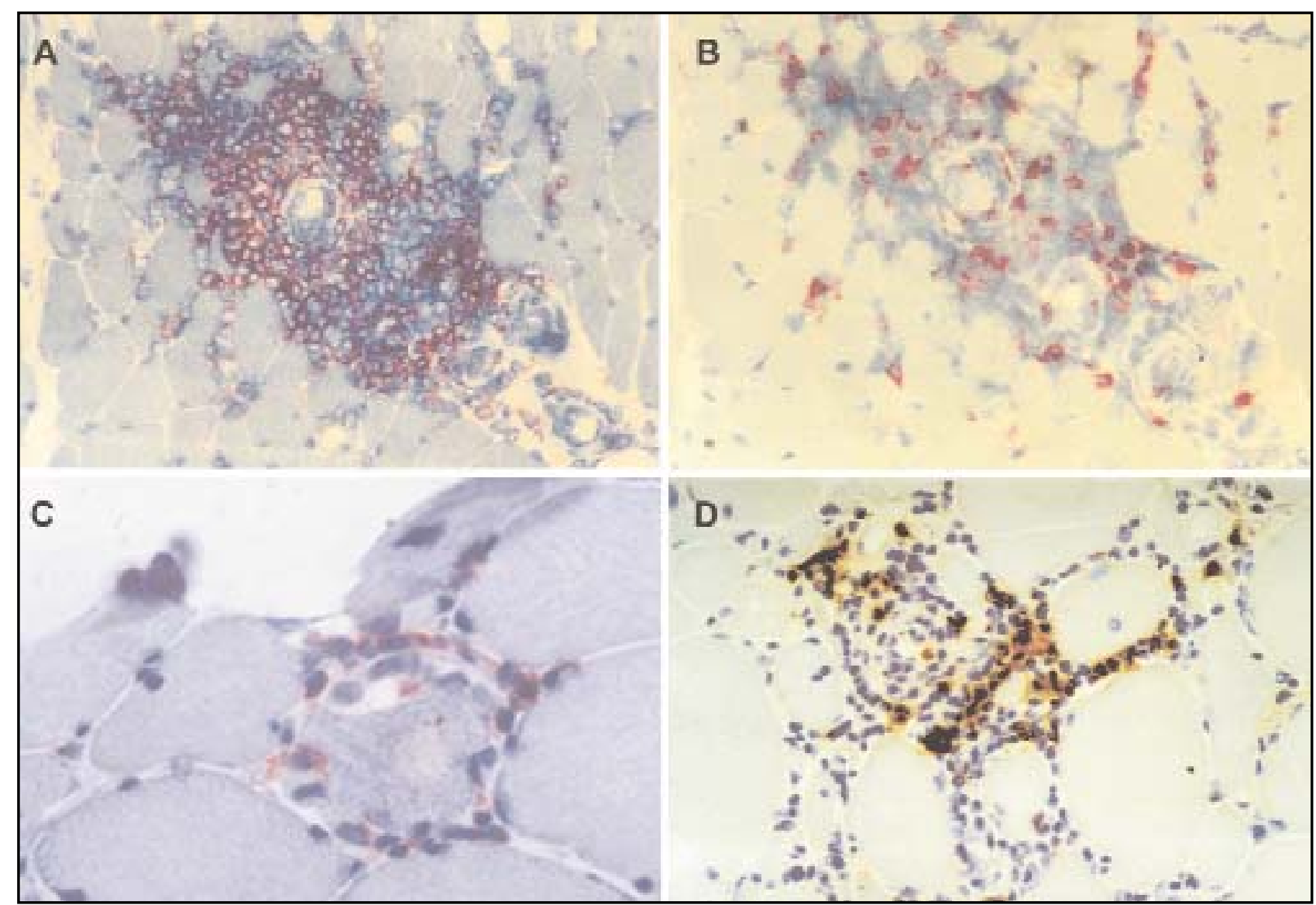

Fig 3. Frozen sections of bíceps brachii from a MCTD patients $(4 \mu, 300 \mathrm{X})$. Immunohistochemical preparations by EnVision technique (in red) ( $A, B$ and $C$ ), and by $L S A B+$ technique (in brown) (D). A and B are sequencial transverse sections showing the predominance of CD4 T cells (A) over CD8 T cells (B) in a perimysial and perivascular inflammatory infiltration. CD8 T cells surround and invade non-necrotic muscle fiber (C). B cells are also present predominantly on perivascular region, both arround endomysial (D) and perimysial vessels.

No proliferation of connective tissue wasobserved on DM and PM samples.

As expected, proliferation of connective tissue was the main finding on the NINMD group, which also presented some degree of necrotic muscle fibers and a sparse inflammatory infiltrate, with exception of the fascioscapulohumeral dystrophy case (Case 30) which had an important inflammatory infiltrate.

\section{Immunohistochemical results}

Expression of MHC class I and class II

The expression of MHC-I was present both on invaded fibers and sarcolemmal membrane in MCTD (Fig 2A). Its positivity was uniformly scarce, and significantly lesser than PM and DM $(p \varangle 0.001)$ (Tables 1 and 3). Importantly, degenerated and normal fiberssurrounded by inflammatory cells in MCTD (Fig $2 \mathrm{~A}^{*}$ ) and PM expressed MHC-I, as necrotic and degenerated fibers mainly in perifascicular region.
The expression of MHC-II wason invaded fibers, on fibers presenting intermyofibrillar abnormalities, and on fiberswith any degree of necrosis. The reactivity of MHC-II on invaded fiberswassignificantly slighter on MCTD $(p=0.012)$ compared to controls. Of note, sarcolemmal membrane MHC-II expression was positive in MCTD on the perifascicular region, as in DM (Table 1 and 3) (Figs 2B and 2F).

All vesselsand capillaries were consistently positive to MHC-II, allowing an estimation of tissue perfusion based upon an analysis of the number of vessels compared to the number of myofibers. This ratio wassignificantly higher in PM (median 0.57, range 0.29 to 1.08), compared to MCTD (median 0.33 , range 0.17 to 0.83 ), which was similar to DM (median 0.24 , range 0.18 to 0.33 ) and NINMD (median 0.38 , range 0.16 to 0.87 ), with significant difference among those groups $(p=0.015)$ (Table 1 ).

Different degrees of vessel depletion were observed in all groups, when a proportion of two vessels 
Table 3. Expressions of MHC-I, MHC-II, ICAM-1, VCAM-1, and C5b-9 on vessels and muscle fibers of MCTD, PM, DM, and NINMD groups.

\begin{tabular}{|c|c|c|c|c|c|}
\hline & $\begin{array}{l}\text { MCTD } \\
(n=14)\end{array}$ & $\begin{array}{c}P M \\
(n=8)\end{array}$ & $\begin{array}{c}D M \\
(n=5)\end{array}$ & $\begin{array}{c}\text { NINMD } \\
(n=4)\end{array}$ & $\mathrm{p}$ \\
\hline \multicolumn{6}{|l|}{ MHC-I } \\
\hline Vessels & 43 & 100 & 80 & 25 & 0.16 \\
\hline Invaded fiber & 7 & 62 & 100 & 0 & $\varangle 0.001$ \\
\hline Sarcolemmal membrane & 7 & 62 & 100 & 0 & $\varangle 0.001$ \\
\hline \multicolumn{6}{|l|}{ MHC-II } \\
\hline Vessels & 100 & 100 & 100 & 75 & 0.10 \\
\hline Invaded fiber & 0 & 25 & 60 & 0 & 0.0119 \\
\hline Sarcolemmal membrane & 0 & 12 & 40 & 0 & 0.07 \\
\hline \multicolumn{6}{|l|}{ ICAM-1 } \\
\hline Vessels & 0 & 12 & 80 & 0 & 0.012 \\
\hline Invaded fiber & 0 & 0 & 80 & 0 & 0.001 \\
\hline Sarcolemmal membrane & 0 & 0 & 20 & 0 & 0.26 \\
\hline \multicolumn{6}{|l|}{ VCAM-1 } \\
\hline Vessels & 0 & 12 & 40 & 0 & 0.063 \\
\hline Invaded fiber & 0 & 0 & 20 & 0 & 0.26 \\
\hline Sarcolemmal membrane & 0 & 0 & 0 & 0 & - \\
\hline \multicolumn{6}{|l|}{ C5b-9 } \\
\hline Vessels & 35 & 37 & 80 & 0 & 0.18 \\
\hline Invaded fibers & 0 & 37 & 40 & 0 & 0.07 \\
\hline Sarcolemmal membrane & 0 & 12 & 0 & 0 & 0.53 \\
\hline
\end{tabular}

to one fiber was considered as normal. This depletion was more evident in DM, as expected. However, interestingly, it wasgreater in MCTD than in PM.

\section{Expression of adhesion molecules}

(ICAM-1, VCAM-1), and C5b-9

The intensity of expression of ICAM-1, a constitutive endothelial adhesion molecule, on vessel wall wassignificantly different among groups $(p=0.012)$ and revealed a weak pattern in the MCTD which was similar to PM, but different from DM (Tables 1 and 3). In MCTD, ICAM-1 expression wasobserved on vessels surrounded by inflammatory cells (Fig 2C). Similarly, ICAM-1 expressed on invaded muscle fibers was positive in $80 \%$ of DM cases. On the other hand, the expression on the membrane of muscle fibers was similarly slight among the four groups $(p=0.26)$.

In contrast, there was no difference in the expression of VCAM-1, an inducible adhesion molecule, on vessels among all groupsstudied $(p=0.06)$. Some PM (1 out of 8) DM (2 out of 5) presented +2 reaction, in contrast to +1 expression in MCTD (14 out of 14). Similarly, in MCTD, VCAM-1 was posi- tive on vessels among or near inflammatory infiltrate (Tables 1 and 3) (Fig 2D).

The apparent lower expression of C5b-9, membrane attack complex (MAC), on vessels in MCTD (Fig 2E) compared to controls did not reach statistical significance $(p=0.18)$. In addition, the MAC expressed in the membrane wasscarce in the majority of all groups studied (Tables 1 and 3).

Phenotyping of infiltrating mononuclear cells

Macrophages (CD68) were one of the predominant cell of the inflammatory infiltrate in all groups, and it was statistically lower in MCTD than PM $(p=0.024)$ and DM $(p=0.035)$ (Graphic 1$)$.

Similarly, the CD45RO+ (memory T cells) were also predominant in the inflammatory infiltrate and they were more frequently found on PM and DM, compared to MCTD and NINMD $(p=0.005)$. On the other hand, CD45RA (virgin T cells) and NK cells (natural killer) were rarely seen in the infiltrate in all groupsand no significant difference was detected among them ( $p=0.07$, and $p=0.4$, respectively) (Graphic 1 ).

In MCTD myositis the $\mathrm{CD}^{+}{ }^{+} \mathrm{T}$ cells predominate at perivascular than at endomysial regions, but 


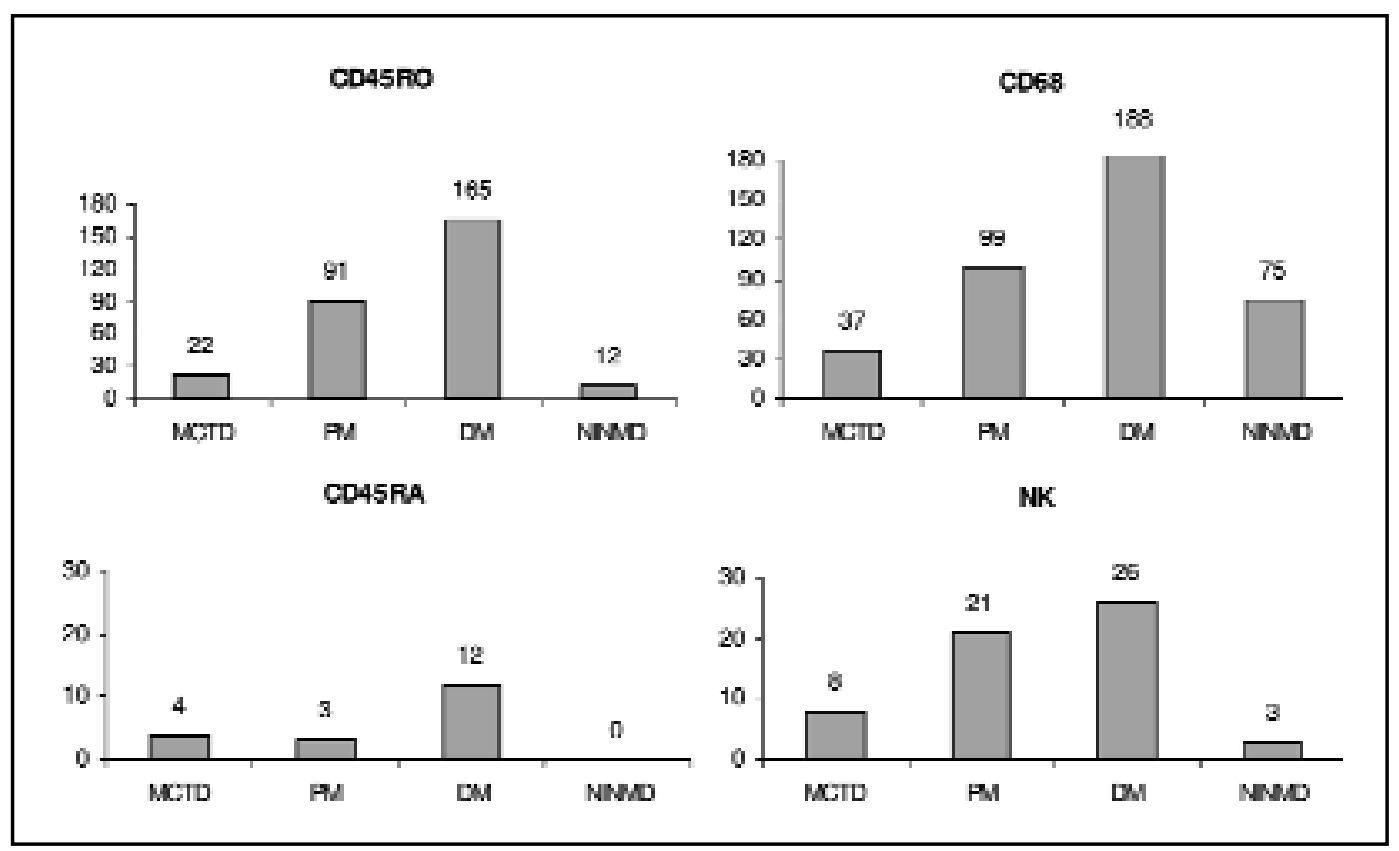

Graphic 1. Median of the absolute number of CD45RO (memory T cells), CD45RA (naive T cells), NK (natural killer cells) and CD68 (macrophages) counted in all specimens (10 fields in $400 \mathrm{x}$ ), in MCTD, PM. DM and NINMD biopsies and a comparison among groups.

\section{MCTD}
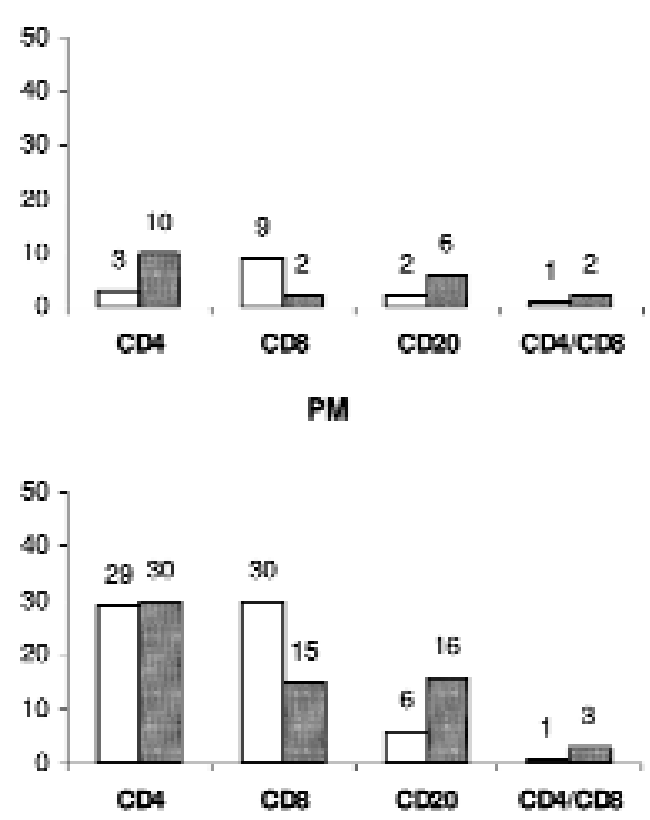

\section{$\square$ Endomysial $\square$ Perivascular}

DM
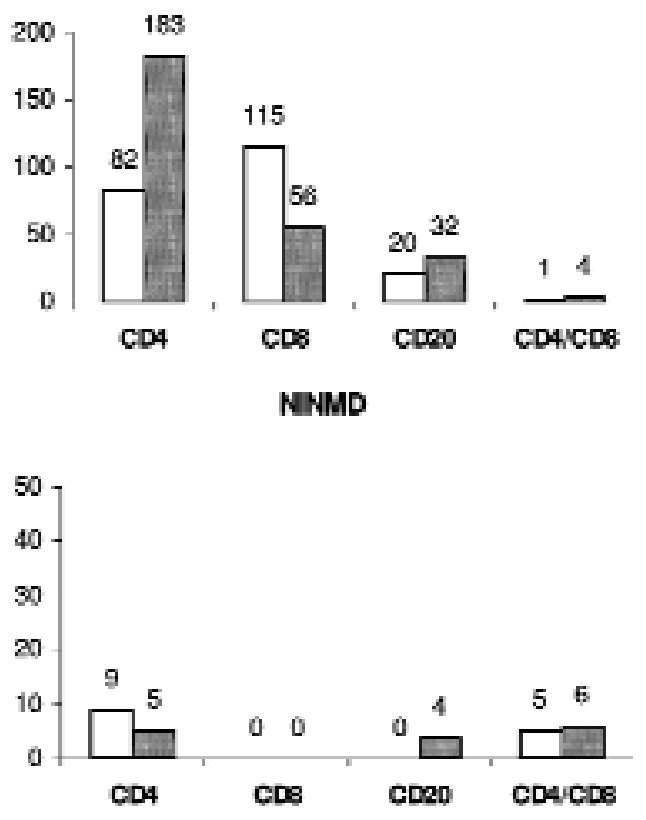

Graphic 2. Median of the percentage of CD4 T cells, CD20 B cells, and the ratio CD4/CD8 in relation to the total number of cells of the inflammatory infiltrate on perivascular and endomysial regions on MCTD, PM, DM and NINMD groups. 
despite the difference, it did not reach statistical significance $(p=0.057)$ (Fig $3 A$ ). The $C D 8^{+} T$ cellswere present more often in endomysial region than at perivascular region ( $p=0.007$ ) (Graphic 2, Figs 3B, 3C). Similarly to helper T cells, B cells (CD20) were more abundant at perivascular than at endomysial sites ( $p<0.001$ ) (Graphic 2, Fig 3D). Consequently, the CD4/CD8 ratio washighest at perivascular than at endomysial site ( $p=0.017)$ (Graphic 2$)$.

In DM, there were a prevalence of CD4 T cells at perivascular region, and B cells (CD20) distribution on perivascular and endomysial region. Therefore, there washigher CD4/CD8 ratio at perivascular than at endomysial site (Graphic 2).

On PM, the $\mathrm{CD}^{+} \mathrm{T}$ cells at perivascular region were quite similar to endomysial region with a predominance of $\mathrm{CD} 8^{+} \mathrm{T}$ cells at endomysial region, and B cells (CD20) at perivascular site. Therefore, the CD4/CD8 ratio at perivascular and endomysial was 3:1 with no statistical difference (Graphic 2).

In NINMD control group, B cells were slightly more common in perivascular region with no difference between the CD8 at endomysial and perivascular regions, and a slight predominance of CD4 at endomysial region than at perivascular site. Consequently, there were a higher CD4/CD8 ratio endomysially than at perivascular site (Graphic2).

In summary, the percentage of lymphocyte Thelper $\mathrm{CD} 4^{+}$were more frequently found in the perivascular than endomysial region of MCTD and DM but not in PM. The percentage of lymphocytes T cytotoxic $\mathrm{CD}^{+}{ }^{+}$, were frequently detected in the endomysial than perivascular region in all groups, except in NINMD, mainly in PM but without statistical difference among groups. The percentage of B cells (CD20) was similar in all groupsstudied (Graphic 2).

\section{DISCUSSION}

This is the first immunohistochemical study to provide clues to the pathogenesis of MCTD myositis. This study suggests that the myositis in MCTD may represent a unique syndrome, with elements of PM and DM, characterized by relatively low CKs, abnormally decreased vessel density, low expression of MHC-I, ICAM-1, and VCAM-1, with predominance of CD45RO cells and macrophages at inflammatory infiltrate, and CD4 and B cells mainly distributed on perivascular site.

Other investigatorshave described MCTD myopathy with PM pattern ${ }^{2,3,8}$, when analyzed by clinical and histological features. On the other hand, Dalakas $^{1,17}$ and others ${ }^{18}$ had described that the myopathy in MCTD resembled more to DM, based on clinical observation.

Histochemical reactions of all MCTD cases in this series revealed the presence of non-necrotic invaded muscle fibers associated with predominant endomysial and perivascular involvement which confersa pattern similar to PM in accordance to the previous descriptions on the literature ${ }^{2,3,19}$.

However, the present results also demonstrated a remarkable decrease in the number of vesselsobserved in the quantitative analysisand a presence of endothelial thickness associated to a perivascular inflammatory infiltration, which indicate a role of vascular pathology in MCTD myositis. The depletion of blood vessels has already been described on initial phase of $\mathrm{DM}^{20}$, which is also preceded by MAC deposition on blood vessels. Interestingly, vascular involvement associated to immunoglobulin deposition has been reported in a few MCTD patients more than 20 years ago ${ }^{7}$. In this regard, proliferative vascular lesions which are a consequence of intimal and medial thickening of blood vessel wall due to inflammatory cell infiltration were observed in the MCTD muscle of autopsy cases by Singsen et al. ${ }^{9}$. Although this type of vascular lesion is the characteristic injury of scleroderma, the findings of perivascular inflammatory infiltration, absence of fibrosisand no fibrinoid vas cular change observed in this study support the hypothesis that the vascular involvement in MCTD muscle differs from those of scleroderma.

On the other hand, detection of MAC on muscle vessels of these patients also raises the question whether the complement system may contribute to the pathogenic mechanism in M CTD myositis. A growing body of evidence demonstrates the important role of capillary injury by MAC in the early phased of muscle involvement of $D^{20,21}$.

The expression of ICAM-1, a constitutive adhesion molecule, on vessels was observed in our MCTD cases. Although its reactivity was detected in few vessels, it waspositive in all cases, which also emphasizes the importance of the vascular component in the immunopathogenesis of MCTD muscle injury. It may be relevant that preferential ICAM-1 upregulation on endothelial cells of perimysial vessels and capillaries was previously described in $\mathrm{DM}^{1,22}$. The reactivity observed at remote sites from inflammatory cellsinfiltration also suggestsa nonlocal factor triggering its expression in MCTD. In this regard, Okawa-Takatsuji et al. ${ }^{23}$ 
recently demonstrated that autoantibodiesagainst U1-ribonucleoprotein (U1-RNP), a biological marker of MCTD, can up-regulate ICAM-1 expression on endothelial cells of pulmonary artery, suggesting that this autoantibody may play an important role in the immunopathological processes leading to a proliferative vasculopathy.

Similarly, the expression of the VCAM-1 wasnoted on endothelial cells of some arterioles surrounded by inflammatory cells. A widespread expression of VCAM-1 has been described in rheumatoid arthritis, AIDS encephalitis, and other conditions ${ }^{22}$. Its expression is not striking in DM and PM, suggesting that thisinducible endothelial adhesion molecule does not play an important role in the pathogenesis of those inflammatory myopathies. Further studieswill be necessary to determine more detailsabout their participation in MCTD myositis.

In addition, the MHC-II expression on degenerated fibers, remarkably on those with a reticular intracytoplasmic pattern on perifascicular region, also showsthe importance of the vascular component in the pathogenesis of MCTD muscle injury, as already described in $\mathrm{DM}^{1}$.

MHC-I positive muscle fibers in our MCTD patients were restricted to endomysial non-necrotic invaded fibers that were surrounded and invaded by $\mathrm{CD}^{+}$cytotoxic $\mathrm{T}$ cell, prevailing over $\mathrm{CD} 4^{+}$on the endomysial region. In fact, Engel and Araha$\mathrm{ta}^{24,25}$ described a PM pattern which is characterized by a progressive positive gradient fro $C D 8^{+} T$ cells from perivascular to endomysial region that was further confirmed by other investigators ${ }^{26-28}$.

In agreement with these data, our observations also indicate the existence of a cytotoxic cell mediated injury. However, these findings were observed in scattered muscle fibers suggesting that the cellular immune response although present may not be the major mechanism involved in MCTD. Conversely, the prevalence of $\mathrm{CD}^{+}{ }^{+}$over $\mathrm{CD} 8^{+} \mathrm{T}$ cell associated to the presence of $B$ cells on perivascular region advocates for a vascular involvement and a probable humoral participation in MCTD myositis.

The inflammatory cell infiltrate of MCTD muscle observed herein hasa dual interesting characteristic: one that resembles $\mathrm{PM}$ in the endomysial region, and the other that resembles DM in perimysial region. However, a significantly fewer total number of T cells is observed in MCTD compared to that observed in PM and DM which is also as- sociated to a smaller number of macrophages, reflects a lower degree of the inflammatory process in MCTD in relation to both the other inflammatory muscle diseases.

In summary, our findings support the notion that muscle involvement in MCTD isa preponderant vessel targeted disease with a probable humoral role, and a concomitant minor cytotoxic immune response. Further studiesto evaluate the role of pro-inflammatory cytokines and U1-RPN antibodies in perpetuating muscle injury are required for a better understanding of the immunopathogenesis of MCTD.

Acknowlegements - We are indebted to Frederick W Miller, MD, PhD, for his careful review of the manuscript. We also thank Mariko Yokoo, and Alda Wakamatsu for technical help.

\section{REFERENCES}

1. Dalakas MC. Immunopathogenesis of inflamatory myopathies. Ann Neurol 1995;37 (S1):S74-S86.

2. Sharp GC, Irwin WS, Tan EM, et al. Mixed connective tissue disease: an apparently distinct rheumatic disease syndrome associated with a specific antibody to an extractable nuclear antigen (ENA). Am J Med 1972;52:148-158.

3. Bennett RM, O'Connell, DJ. Mixed connective tissue disease: a clinicopathologic study of 20 cases. Sem Arthritis Rheum1980;10:25-51.

4. Karpati G, Pouliot Y, Carpenter S. Expression of immunoreactive major histocompatibility complex products in human skeletal muscles. Ann Neurol 1988;23:64-72.

5. Engel AG, Arahata K. Mononuclear cells in myopathies: quantification of functionally distinct subsets, recognition of antigen-specific cellmediated cytotoxicity in some diseases, and implications for the pathogenesis of the different inflammatory myopathies. Human Pathol 1986;17:704-721.

6. Kissel JT, Mendell JR, Rammohan KW. Microvascular deposition of complement membrane attack complex in dermatomyositis. N Engl J Med 1986;314:329-334.

7. Oxenhandler R, Hart M, Corman L, Sharp G, Adelstein E. Pathology of skeletal muscle in mixed connective tissue disease. Arthritis Rheum 1977;20:985-988.

8. Burdt MA, Hoffman RW, Deutscher SL, Wang GS, Johnson JC, Sharp GC. Long-term outcome in mixed connective tissue disease. longitudinal clinical and serologic findings. Arthritis Rheum 1999;42:899-909.

9. Singsen BH, Swanson VL, Bernstein BH, Heuser ET, Hanson V, Landing $\mathrm{BH}$. A histologic evaluation of mixed connective tissue disease in childhood. Am J Med 1980;68:710-717.

10. Bohan A, Peter JB. Polymyositis and dermatomyositis. N Engl J Med 1975;292:344-347.

11. Bohan A, Peter JB. Polymyositis and dermatomyositis. N Engl J Med 1975;292:403-407.

12. Kurata N, Tan EM. Identification of antibodies to nuclear acidic antigen by counterimmunoeletrophoresis. Arthritis Rheum 1976;19:574-580.

13. Tan EM. Antinuclear antibodies: diagnostic markers for autoimmune diseases and probes for cell biology. Adv Immunol 1989;44:93-151.

14. Laemmli UK. Cleavage of structural proteins during the assembly of the head of bacteriophage T4. Nature 1970;227:680-685.

15. Towbin H, Staehelin T, Gordon J. Electrophoretic transfer to proteins from polyacrylamide gels to nityrocellulose sheets procedure and some applications. Proc Nat Acad Sci USA 1979;76:4350-4354.

16. Dubowitz V, Sewry CA, Fitzsimons. Histochemical and histological stains and reactions. In Dubowitz V (ed): Muscle biopsy: a practical approach. 2. Ed. Philadelphia Saunders, 1995:19-40. 
17. Dalakas MC. Polymyositis, dermatomyositis and inclusion body myositis. N Engl J Med 1991;325:1487-1498

18. Kotajima L, Aotsuka S, Sumiya M, Yokohari R, Tojo T, Kasukawa R. Clinical features of patients with juvenile onset mixed connective tissue disease: analysis of data collected in a nationwide collaborative study in Japan. J Rheumatol 1996;23:1088-1094.

19. Isenberg D. Myositis in other connective tissue disorders. Clin Rheum Dis 1984;10:151-174

20. Mendell JR, Garcha TS, Kissel JT. The immunopathogenic role of complement in human muscle disease. Curr Opin Neurol 1996;9:226-234.

21. Crowson NA, Magro CM. The role of microvascular injury in the pathogenesis of cutaneous lesions of dermatomyositis. Hum Pathol 1996;27:15-19.

22. Bleecker JL, Engel AG. Expression of cell adhesion molecules in inflammatory myopathies and Duchenne dystrophy. J Neuropatol Exp Neurol 1994;53:369-376

23. Okawa-Takatsuji M, Aotsuka S, Fujinami M, Uwatoko S, Kinishita M, Sumiya M. Up-regulation of intercellular adhesion molecule-1 (ICAM-
1), endothelial leukocyte adhesion molecule-1 (ELAM-1) and class II MHC molecules on pulmonary artery endothelial cells by antibodies against U1-ribonucleoprotein. Clin Exp Immunol 1999;116:174-180.

24. Arahata K, Engel AG. Monoclonal antibody analysis of mononuclear cells in myopathies: V. identification and quantitation of T8+ cytotoxic suppressor cells. Ann Neurol 1988;23:493-499.

25. Arahata K, Engel AG. Monoclonal antibody analysis of mononuclear cells in myopathies I: quantitation of subsets according to diagnosis and sites of accumulation and demonstration and counts of muscle fibers invaded by T cells. Ann Neurol 1984;16:193-208.

26. Lemoine NR, Ryan JF, Cox EL, Mayston V, Revell PA, Swash. Immunohistochemical analysis of mononuclear cell subsets in inflammatory and non-inflammatory myopathies. J Clin Pathol 1986;39:271-274.

27. Botet JCP, Grau JM, Casademont J, Urbano-Márquez A, Rozman C. Characterization of mononuclear exudates in idiopathic inflammatory myopathies. Virchows Archiv Pathol Anat 1988;412:371-374.

28. Lindberg C, Oldfors A, Tarkowski. A local T-cell proliferation and differentiation in inflammatory myopathies. Scand J Immunol 1995;41:421-426. 